\title{
The Strategy Option of Inspection and Certification Industry in China
}

\author{
Luogao Wang ${ }^{1}$, Qiang Lu ${ }^{1}$,Zhaoying Zuo ${ }^{2 *}$,Caili Zhang ${ }^{1}$, Hongjuan \\ Yang $^{1}$,Yan Wang ${ }^{2}$, Kai Li $^{2}$
}

\author{
${ }^{1}$ Rizhao Entry-exit Inspection and Quarantine Bureau, Rizhao,276800,China. \\ ${ }^{2}$ Rizhao Inspection \&Certification Co., Ltd, Rizhao, 276800,China. \\ *Correspondence author: zuozhaoying0531@sina.com
}

\begin{abstract}
Inspection and certification industry is the national quality foundation and an important part of modern service industry in China. The industry has been regarded by the State Council as one of the eight high technology service industries and eleven largest producer services. The paper is one of the first to analysis the process of conspiring and the act of one single game between supervisors and inspection bodies. Then the paper proposes some measures to enhance the competitiveness of the inspection and certification industry .
\end{abstract}

Keywords: Inspection and certification; Game theory; Strategy option

\section{Introduction}

Inspection and certification industry is not only the national quality foundation but also an important part of national innovation system and modern service industry in China . They have been regarded by the State Council as one of the eight high technology service industries and eleven largest producer services. The scale of inspection and certification market in China had been more than 100 billion yuan in 2013 and become the third largest market, rank only second to the United States and the European Union area, which is expected to exceed 250 billion RMB by the year 2020. We can see size of quality inspection industry from figure1.

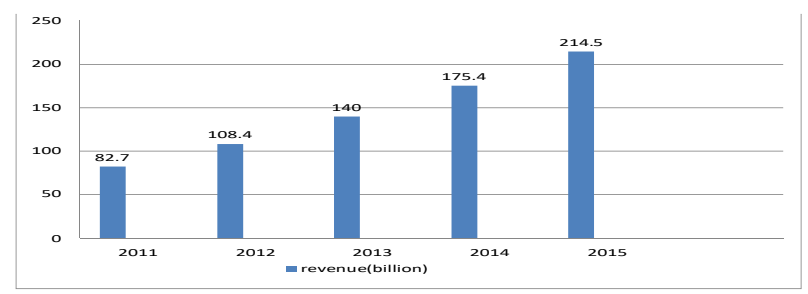

Figure 1 Size of Quality Inspection Industry from 2011-2015（From AQSIQ )

The characteristic of China's inspection and certification industries is as follows. Firstly, inspection and certification bodies are small and segmented compared with international institution. Annual report shows that the annual income of SGS, Intertek, BV counted for RMB 42.5,20.1,28.9 billion(Figure 1), whereas China's largest inspection certification group income earns less than 10 billion yuan.Secondly, the technical strength and brand influence remains to be further improved. 
More than ninety percent of nickel ore imported by China recent years were inspected by foreign inspection institutions. In addition, many mines like CVRD, BHP are inclined to foreign inspection bodies for protective inspection. Although the number of Chinese certificates is the largest in the world, for the new areas, new technology in international certification and accreditation, China almost in the stage of tracking research and accept the evaluation standard and system passively. Thirdly, the supervision ability need to be further enhanced. The current authority and ability between departments of the state council and certification and accreditation administration shows a little weak. Phenomenon like repeated evaluation, not admit the evaluation results of each other often happened. Fourthly, the government funding is not enough. The U.S. national standards and technology institution where responsible for the standardization policy of government departments, get $\$ 769$ million from the U.S. government in 2013, whereas the institutions which responsible for the national quality infrastructure CNIS, NIM, the state administration of quality infrastructure get less than 700 million yuan a year. Therefore it is meaningful to research the topic of Inspection and Certification Industry.

\section{Literature Review}

The origin of certification service can be traced back to the establishment of Lloyd Register in England during 1760s. Certification services have restored in China since the membership of China in ISO resumed in 1978. In 2001, the Certification and Accreditation Administration of China is established to manage, supervise and coordinate various kinds of certification service in China. With the open market policy in the certification industry since 2006, the number of certification bodies has grown in China from 137 accredited certification bodies in 2005 and 158 in March 2017. Multiple players, together with strict regulations and demanding customer requirements, make certification bodies have to pay more attention to the service quality. Strausz R.(2004) and Huang Xin et al.(2009)discuss of honest certification and the threat of capture. Terziovski, M. and Power, D. (2007)discuss the role and the skill of auditors in certification bodies. Hatanaka $M$ and Busch L(2008) hold a view that government should strengthen the management over certification bodies, and set unified certification standards democratically in a scientific way. Also no system would play its role efficiently unless third party certification is conducted under a government and non-government joint governance mechanism. Miao C.H (2009) pointed out that a monopolistic certification institution would follow certification standards more easily to conduct certification honestly.. Su Qin et al.(2010)explore the service quality of certification body. The authors explore and analyze quality characters of certification service industries. The different customers' quality evaluations levels are significantly different. In the current certification market, fully understanding the developmental status and clearly understanding the needs of customers are extremely important. Jin, B et al(2012) point out that regulation based on open and fair will be the fundamental principal of building up the regulation system according to the market economic system. We need to learn from international experience while give more play to the inspection and certification bodies and associations, constantly improve China's regulation system, turning it into a multidimensional system that is based on market process and are able to mobilize the power of different aspects. Castka, Pavel et al.(2015) research the choice of certification body by firms. Liu R et al.(2015) apply the fuzzy SERVQUAL method to measure the service quality by the example of China Inspection and Certification Company. Zuo Z\&Tang D. (2017)discuss the effective of ISO9001 certification on firms' performance. Zuo Z et al(2017)discuss how to measure the ISO9001 implementation effectiveness and the strategy of certification industry in China.

Game theory is "the study of mathematical models of conflict and cooperation between intelligent rational decision-makers". The game theory model consists of three components: player, 
strategy, and pay-off. The player is an agent who participates in the game and each player has his own strategies with different pay-offs. With this basic setting, the main purpose of game theory is to derive an equilibrium in the game depending on the players and their strategies. it originally addressed zero-sum games, in which one person's gains result in losses for the other participants. Today, game theory applies to a wide range of behavioral relations, and is now an umbrella term for the science of logical decision making in humans, animals, and computers. Modern game theory began with the idea regarding the existence of mixed-strategy equilibria in two-person zero-sum games and its proof by John von Neumann. Game theory is mainly used in economics, political science, and psychology, as well as logic, computer science and biology. Chen, T., \& Jiang, Y. (2017)establishes a supply chain enterprises operating mechanism model from the perspective of game theory, uses repeated game, individual game and group of evolutionary game, verifies the importance of cooperation in creative products supply chain through theoretical proof and examples. Kim, K., Jung, S., Hwang, J., \& Hong, A. (2017)proposed a new standardization framework by combining network analysis and the game theory model.Chen, Y., Yeh, A. G. O., \& Zhang, Y. (2017) studied the political incentives of government officials to cooperate with one another to achieve a common goal through game theory.

From above papers,we can see only few of paper analysis the certification and inspection industry by game theory and few of paper discuss the strategy development of inspection and certification industry in China.

\section{Economic analysis of Inspection and certification Industry}

Take nickel ore inspection as an example. The main relevant parties of inspection process include supervisor, buyer, seller and inspection body. If the true value of the result is $N_{1}$ and the test error is $\alpha$. because the technology of taking sample, preparing sample and testing, the results of inspection bodies released are $N_{2}$.

$$
N_{2}=N_{1}+\alpha
$$

The error $\alpha$ is inevitable and acceptable by buyer and seller. If the inspection body modified the data for the buyer, making the result is $N_{3}$. The total revenue of conspiring is $R=R(\Delta N)$, $\Delta N=N_{3}-N_{2}$. If the probability of conspiring is $x$ and the probability of detected by the supervisor is $y$, as follows

Table 1 Game Matrix Between supervisor and Buyer/Inspection Body

\begin{tabular}{|c|c|c|}
\hline supervisor & Detected $y$ & Not detected : $(1-y)$ \\
\hline Conspire: $x$ & $x y$ & $x(1-y)$ \\
\hline Not conspire: $1-x$ & $(1-x) y$ & $(1-x)(1-y)$ \\
\hline
\end{tabular}


If the conspire is detected, the penalty is $p 1$ (the buyer) and $p 2$, the cost of supervisor is $c$, The award of the supervisor is $k(p 1+p 2)$, the rang of $k$ is from the number of 0 to 1.If the amount of expenses of supervisor is $I\left(N_{2}\right),\left(I^{\prime}\left(N_{2}\right)>0\right)$. In one single game, the earnings of inspection is $g^{\prime}\left(N_{2}\right), \quad\left(g^{\prime}\left(N_{2}\right)>0\right)$. Expected utility function of each party is as follows:

$$
\begin{aligned}
U^{b} & =W\left(N_{2}\right)+x\left[c_{1} R^{*}(1-y)-y c_{1}\right] \\
U^{i} & =g\left(N_{2}\right)+x\left[c_{2} R^{*}(1-y)-y c_{2}\right] \\
U^{r} & =I\left(N_{2}\right)+x y k\left(p_{1}+p_{2}\right)-y c
\end{aligned}
$$

$c_{1}$ and $c_{2}$ are the ratio of conspiring by buyer and inspecting body, the range of each is no less than 0 and together of the two are $100 \%$.

From (2)-(4), we can conclude that the buyer, inspection body can raise the probability of conspiring and $\mathrm{N}_{3}$. In order to prevent the situation, supervisor can adjust variable y $c_{1}$ and $c_{2}$ affect the revenue of buyer and inspection and testing body. The first derivative of $U^{b}$ and $U^{i}$ with respect to $x$ is

$$
\begin{aligned}
\frac{\partial U^{b}}{\partial x} & =0 \longrightarrow y^{*}=\frac{c_{1} R}{p_{1}+c_{1} R} \\
\frac{\partial U^{i}}{\partial x} & =0 \longrightarrow y^{*}=\frac{c_{2} R}{p_{2}+c_{2} R}
\end{aligned}
$$

We can judge that $\frac{\partial y^{*}}{\partial\left(c_{1} R\right)}>0, \frac{\partial y^{*}}{\partial\left(p_{1}\right)}<0, \frac{\partial y^{*}}{\partial\left(c_{2} R\right)}>0, \frac{\partial y^{*}}{\partial\left(p_{2}\right)}<0$, In order to get more conspire revenue, the more buyer and inspection testing body $\operatorname{get}(R)$, the more probability of detected by supervisor. Accordingly

$$
\frac{\partial U^{R}}{\partial y}=0 \rightarrow x^{*}=\frac{c}{k\left(p_{1}+p_{2}\right)}
$$

We can see from (7) $\frac{\partial x^{*}}{\partial c}>0, \frac{\partial x^{*}}{\partial\left[k^{*}\left(p_{1}+p_{2}\right]\right.}<0$. The less the cost of regulation or the more of the reward, the more the supervisor want to supervise the conspire .

The certification and other commodity of inspection and testing can analyzed according to above analysis.

\section{Strategy option on developing the industry in China}

Firstly, we should actively introduce high-level talents with rich experience of global market and management into management positions in inspection and certification companies. Also we should try to draw lessons from independent system of American accountants industry in order to overcome the shortage of lacking transparent supervision. State-owned enterprises are divided into two categories, that are the business and the public. We can explore the restructuring of different categories of certification industries and part of the inspection and certification companies could be brought into the public class state-owned enterprises. Then we should encourage mainly non-state capital investment take part in state-owned enterprises reform through ways like participate in 
shareholder, subscribe convertible bonds, equity transfer. Also we should encourage state-owned capital investment to become a shareholder of non-state inspection and certification companies in many ways and encourage them to form into allies.

Secondly, One of the important measures to promote core competitiveness is to exert synergistic effect after integration and reconstruction. We should grasp the historical opportunity of " made in China 2025". Foreign comprehensive large-scale inspection bodies launched large-scale mergers and acquisitions worldwide in recent years and had entered a new market quickly. We should study the development models of overseas inspection and certification bodies and vigorously promote restructuring of domestic inspection and certification industry. Then we should support domestic institutions expand to abroad actively with support of finance and tax policy. Also we should Learn from foreign institutions practices such as Australia and New Zealand. The two countries set up a joint system certification and accreditation institution. We can also deepen certification and accreditation cooperation mechanism with other countries. At the same time, we should enforce international exchanges and study experience from abroad such as France, the Czech republic and Poland .In these countries, they obtained most of inspection services results from the third party and third party adoption can make supervisors from multifarious daily affairs and make supervision well.

Thirdly, we should enhance the application of big data and e-commerce in inspection and certification industry. Also we should improve the supervision mechanism in or after the event and local government department or local associations could evaluate the effectiveness of local inspection and certification institutions by the index system and model. We should set up a compensation fund which is similar to reserve requirements of the bank. Inspection and certification institutions with higher percentage of poor record should hand in more and to those institutions with no bad records hand in less. If serious problems happened, the supervision department could coordinate and take fund for compensation which is similar to build sponsors system in the securities markets to strengthen the supervision of institutions .

Fourthly, we should take measures continuously to perfect the market economic system and improve the social credit system which conforms to Chinese conditions. Also we should update the related regulations timely and strengthen punishment and public notification. Then we should spread inspection and certification knowledge into the factory and communities. Also we should set up funds and other ways to mobilize the mass enthusiasm on reporting violations of inspection and certification orders . Finally relevant department should perfect complaint handling systems and procedures in order to timely handle complaints.

Conclusions

Based on the game theory and information economics, the paper is one of the first to analysis the process of conspiring and the act of one single game using the nickel ore inspection. Then the paper studies the situation of inspection and certification industry in China .Also the paper proposes some measures to enhance the competitiveness of the industry in China. .

The paper also has some limitations. Firstly, the paper does not analysis the actions of players by dynamic game theory. Secondly, the paper does not analysis the strategy option in detail. Thirdly, the paper does not compare the differences and similarities of inspection and certification industry. These are the directions of further study. 


\section{Reference:}

[1]Castka P, Prajogo D, Sohal A, et al. Understanding firms' selection of their ISO 9000 third-party certifiers[J]. International Journal of Production Economics, 2015, 162:125-133.

[2]Chen, T., Jiang, Y. Research on operating mechanism for creative products supply chain based on game theory[J]. Discrete and Continuous Dynamical Systems-Series , 2017,8(6):1103-1112.

[3]Chen, Y., Yeh, A. G. O., Zhang, Y. . Political tournament and regional cooperation in china: a game theory approach[J]. Annals of Regional Science, 2017,58: 1-26.

[4]Kim, K., Jung, S., Hwang, J., \& Hong, A.. A dynamic framework for analyzing technology standardisation using network analysis and game theory[J]. Technology Analysis\&Strategic Management 2017,394:1-16.

[5]Liu, R., Cui, L., Zeng, G., et al.. Applying the fuzzy servqual method to measure the service quality in certification \& inspection industry[J]. Applied Soft Computing Journal, 2014,26: 508-512.

[6]Miao,C.H. Competition in quality standards[J]. Journal of Industrial Economics, 2009,57(1):214-214.

Su, Q., Cui, Y. W., \& Dang, J. X.. A study on measuring service quality in b2b context based on certification service industry[J]. Management Review, 2010,22(7):105-114.

[8]Strausz R. Honest Certification and the Threat of Capture[J]. Discussion Paper, 2004, 23(s $1-2): 45-62$.

[9]Terziovski, M., Power, D. Quality Audit Roles and Skills: Perceptions of Non-financial Auditors and their Clients[J]. Journal of Operations Management, 2007,(28):73-77.

[10]Zuo Z, Tang D. Research on the impact of ISO9001 certification effectiveness on organizational performance in China[J]. Boletin Tecnico/technical Bulletin, 2017, 55(4):644-655.

[11]Zuo Z,Wu S,Li H.et al. Evaluation of ISO9001 implementation effectiveness based on AHP-FUZZY comprehensive evaluation method [J]. Boletin Tecnico/technical Bulletin, 2017, 55

(7) :354-366

[12]Zuo Z, Zhang Y, Wang L, et al. Research on Inspection Testing and Certification Industry in China[C]// International Conference on Management Science and Innovative Education. 2016.

[13]Zuo Z. Sun J. Chang Z.et al.Research on Development Strategy of China's Certification Industry[J]. Revista de la Facultad de Ingeniería，2017,32（14） : 894-898 